\title{
Research on the Mechanism and Effects of Trait Affect on Procedural Justice Perceptions in Performance Appraisal
}

\author{
Qiuhang $\mathrm{Xu}^{1, \mathrm{a}}$, Weidong Jiang ${ }^{2, \mathrm{~b}}$ \\ ${ }^{1}$ School of Economic \& Management, Nanjing University of Science \& Technology, Nanjing, 210094, \\ China \\ ${ }^{2}$ School of Economic \& Management, Nanjing University of Science \& Technology, Nanjing, 210094, \\ China \\ aemail: xqh_0814@163.com, bemail: njust0909@163.com
}

Keywords: Trait Positive Affect; Trait Negative Affect; Procedural Justice Perceptions in Performance Appraisal; Perception of Organizational Politics

\begin{abstract}
Based on the theoretical analysis and literature research, this study constructs the effect mechanism of ratee's trait affect on procedural justice perceptions in performance appraisal, and validates the model by the following-up data. The results show that ratee's trait positive affect has a significant positive effect on the two dimensions of procedural justice perceptions in performance appraisal (perception justice of the system、 perception justice of raters), trait negative affect has a significant negative effect on the perception justice of the system and raters; and perception of organizational politics mediates the relationship between trait affect and perception justice of the system and raters.
\end{abstract}

\section{Introduction}

It is indicated in more than four decades of research on organizational justice that justice perceptions matter a great deal, which is an important determinant of work attitudes, decisions and behaviors [1]. Most of the researches on justice perceptions of affective perspective are state affects, such as those of emotions and moods on justice perception. However, trait affect is different from state affect on connotations and influence mechanism of justice judgment. Trait Affect represents individuals' predisposition to experience like states across time and situations [2]. Based on meta-analysis, Barsky et al[3] found that employees' trait affect has a significant positive effect on organizational justice. But there are few empirical research focused on the influencing mechanism of employees' trait affect on organizational justice.

Procedural justice perceptions in performance appraisal is employees' justice judgment of performance appraisal process in the single context of performance appraisal. In this study, based on Chen's research results [4], we divide procedural justice perceptions in performance appraisal into two parts: perception justice of the system and perception justice of raters. From ratee's affectivity perspective, we discuss the effects and influence mechanism of trait affect on procedural justice perceptions in performance appraisal.

Perception of organizational politics (POPS) refers to organizational members' subjective assessment of the extent of self-interested behavior in the working environment, which includes individual's attribution of self-interest behavior. There are few empirical studies intended to verify the mediating role of POPS between trait affect and organizational justice, especially the influence mechanism of employee's POPS on justice perceptions in performance appraisal n;eeds to be further explored. Therefore, this study uses trait affect as the antecedent variable, introducing POPS as a mediator, to construct the conceptual model of ratee's procedural justice perceptions in performance appraisal' formation mechanism.

\section{Theoretical foundation and research hypothesis}

Perception justice of the system refers to the sense of justice of performance appraisal's system 
itself, which is derived from organizational focus. Different performance appraisal systems have different degrees of justice, in addition to the objective justice of system itself, individuals with different personality traits will also have different subjective perceptions of the system. Our approach, consistent with the research of affect of two-factor model of Watson [2], conceptualizes trait affect as existing along two separate unipolar dimensions, namely trait positive and negative affect. Trait positive affect represents individual's predisposition to experience positive activated emotions such as enthusiastic, active and energetic consistently across time and situations. Trait negative affect represents individual's predisposition to experience negative emotions such as anger, depression and subjective stress consistently across time and situations.

Trait affect is associated with a preference experience, which predicts individuals' judgments through its influence on perception formation and differential reactivity and exposure to environmental events. Those high in TPA tends to view the performance appraisal index system, procedures and policies in a positive and nonthreatening light and are more receptive to performance appraisal indicators and standards, thus are less likely to be resistant to the appraisal system. In contrast, those high in TNA tends to perceive things around in a negative way, often expressing anxiety and stress. For the sake of self-interest, high TNA ratees may question the rationality and fairness of the performance appraisal indicators, and may not recognize and accept performance appraisal criteria.

H1a: TPA has a significant positive effect on justice perception of system.

H1b: TNA has a significant negative effect on justice perception of system.

Perception justice of raters refers to the justice perception of executive attitude and behavior in the procedure of performance appraisal, which is derived from the rater's focus. From the perspective of perceived sensitivity, individual affectivity differences will influence their sensitivity to environmental stimulus. According to Judge et al.'s S-O-R model, trait affect will influence individual's sensitivity to environmental stimulus [5]. During the performance evaluation process, high TPA ratees were more sensitive to raters' positive behavior and were more receptive to the performance improvement recommendations made by the raters. On the contrary, because of their subjective negativity and nervousness, high TPA ratees were easy to question whether unbiased assessment behavior is token, and more sensitive to performance insufficiency and recommendations for improvement proposed by raters during performance communication, resulting in injustice perception of raters.

From the perspective of interpersonal treatment, the difference of individual trait affect will also influence the environmental stimulus itself and the possibility of encountering such stimuli, that is, individuals' affectivity tendencies will shape how others treat and react to them. Because of their proactive behavior and optimism in the process of performance evaluation, high TPA individuals' are more likely to be approached by raters, then get more right to speak and achieve positive feedback in the performance feedback interview. High TNA ratees are more likely to develop negative or hostile relationships. They are often at a disadvantage position in performance feedback process, and have little voice in the process of communication. Raters are more likely to alienate and avoid high TNA individuals in performance feedback.

H2a: TPA has a significant positive effect on the perception justice of raters.

H2b: TNA has a significant negative effect on the perception justice of raters.

Working in an environment full of political behavior, employees will be more vigilant to political behavior in order to ensure their own interests will not be damaged by other's behavior. This vigilance depletes ratees' cognitive and emotional resources, thereby would also undermine one's perceived justice, particularly procedural justice perception. Kacmar et al [6] argue that perception of organizational politics represents the degree to which an individual perceives the existence of political behavior in his work environment (such as: others within the organization through a variety of methods to increase their own interests, but from the perspective of the individual seems to be unfair or unjust). If ratees perceive the setting of appraisal indicators and criteria is manipulated, and appraisal system formulation violates the "unbiased" principle, they would judge appraisal system unfair. 
Dulebohn [7] found that they would have a high sense of justice if subordinates perceive that they have the right to speak and make influence on the performance appraisal process. The theory of group value also suggests that having a voice represents individual is accepted as a member of group, and that acceptance of the perception makes them perceive fair. "Go along to get ahead" is regarded as a political action, which means organization doesn't encourage employees to make suggestions and voice. When employees perceived frequent political behavior within the performance feedback interview process, only through keeping silence can protect their own interests, they would think that the right to voice was deprived, causing injustice perception of rater.

\section{H3: Perceived organizational politics has a significant negative effect on the following} variables: perception justice of system; perception justice of rater.

Individuals' with high TPA are described as having social efficacy, who are more likely to take organizational politics as a pathway of participating in the social activities of the organization, and as a means of seizing the opportunities that arise in the normal activities of the organization[8]. They will not attribute this behavior to negative political means. Moreover, TPA is regarded as a mechanism to reduce the negative perceptions and negative effects associated with politics, so individuals' with high TPA are less likely to perceive negative political behavior. As a result, they have low political perceptions because they rarely make political attributions about organizational decisions. Accordingly, TPA has a significant negative impact on POPS. It is clear from the previous analysis that TPA has a significant positive effect on the perception justice of the system and raters, POPS has a significant negative effect on the perception justice of the system and raters. From the foregoing, it can be proposed as:

H4a: TPA has significant positive effects on the following variables through POPS: (1) perception justice of the system;2)perception justice of raters.

Organizational politics is sometimes considered as a form of obstruction or threat. It limits individual's ability and confidence in achieving his personal or professional goals [9]. Individuals with negative perspectives tend to attribute negative consequences to negative stimulus, and are more likely to perceive external environmental stress, so they are always in a state of "hyper-vigilant". High TNA ratees tend to avoid intimate interactions with others, which making them more easily to be excluded by others and are usually excluded from interest groups. As a result, high TNA individuals often have higher POPS. It is clear from the previous analysis that TNA has a significant negative effect on the perception justice of the system and raters, POPS has a significant negative effect on the perception justice of the system and raters. It is thus proposed as:

H4b: TNA has significant negative effects on the following variables through POPS: (1) perception justice of the system;2)perception justice of raters.

Based on Hypothesis 1 to Hypothesis 4, the theoretical hypothesis model constructed in this study is shown in Fig I.

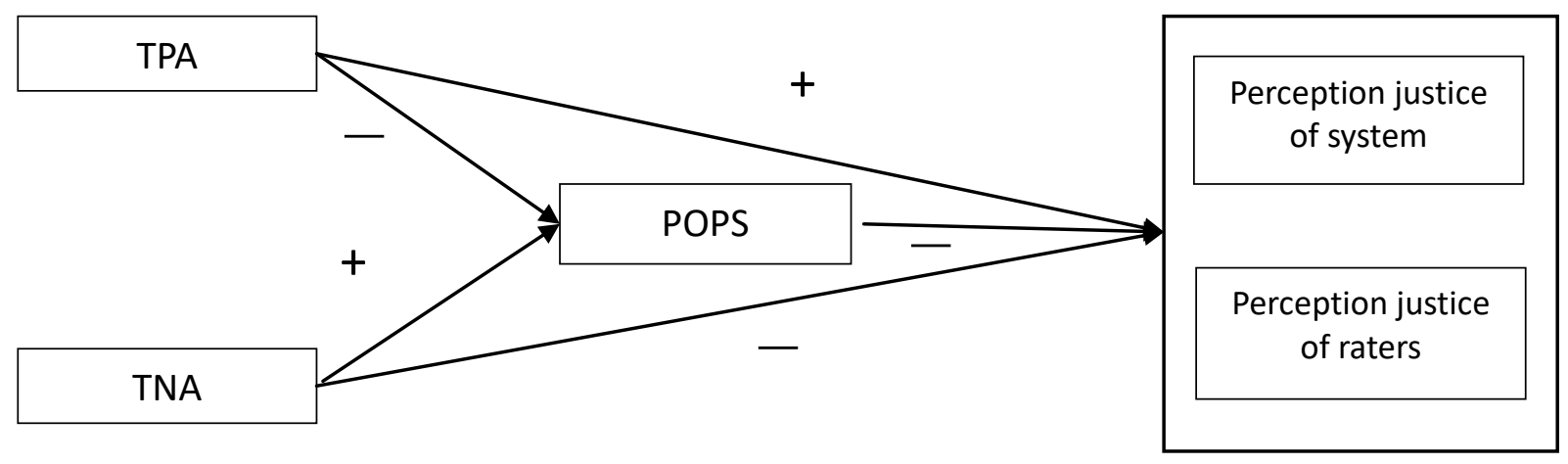

\section{Research method}

Figure I: Theoretical model

Samples and data collection

Questionnaire survey was conducted in 13 enterprises in Shanghai and other cities in Anhui Province, which was conducted by means of on-site questionnaires. All the enterprises surveyed have already carried out formal performance appraisal for more than 3 years. The questionnaire was 
divided into two parts: pre-performance appraisal and post-performance appraisal questionnaire. Pre-evaluation questionnaire includes trait affect and POPS scale, and post-evaluation questionnaire includes procedural justice perception in performance appraisal items and the demographic information items. A total of 550 questionnaires were sent out before the evaluation, 538 questionnaires were returned, 497 questionnaires were valid, and the effective rate was about $90.3 \%$. After enterprises have conducted performance evaluation, we sent post-evaluation questionnaire to the same group of respondents according to employee serial number. Therefore, 497 questionnaires were distributed, 455 questionnaires were returned, and the effective questionnaire was made up of 428 samples. In the 428 questionnaires, 59.1\% were male, 57\% were married. Ages of 30 and below, 31-40, 41-50, 51 and above accounted for 49.8\%, 26.6\%, $17.5 \%$ and $6.1 \%$, respectively. Undergraduate and graduate students accounted for $41.6 \%$ and $27.3 \%$. The sample working in the present unit for $1-5,5-10,10-20$ and 20 years above respectively account for $45.8 \%, 19.9 \%, 13 \%$, $21.3 \%$.

Research tools

Dependent variable: the measurement of procedural justice perception in performance appraisal adopts the scale of 24 items developed by Chen et al [4]. It measures procedural justice perception of performance appraisal from two dimensions: perception justice of system ( 7 items) and perception justice of rater (10 items). The questionnaire used Likert 6-point scale.

Independent variable: the PANAS scale developed by Watson et al[2] was used to measure trait affect, which contains 10 adjectives measure TPA and 10 adjectives measure TNA. It used Likert 5-point scale.

Mediator variables: the measurement of POPS adopts the 15 items scale developed by Kacmar[6] in 1997, which consists of three dimensions: general political behavior, go along to get ahead and pay and promotion policies. It also used Likert 5-point scale.

Control variables: include gender, marital status, age, education, organizational tenure.

\section{Results}

Using SPSS19.0, the reliability analysis reported the following: trait positive affect (Cronbach's alpha $=0.838$ ), trait negative affect (Cronbach's alpha $=0.858$ ), perceptions of organizational politics (Cronbach's alpha $=0.894$ ), perception justice of system (Cronbach's alpha $=0.871$ ), perception justice of rater (Cronbach's alpha $=0.940$ ). The above Cronbach's alpha were all higher than 0.8 , which indicated that reliability of the questionnaire was high.

The measures were also subjected to confirmatory factor analysis using Amos17, as shown in table I. For the pre-performance appraisal questionnaire, five-factor measurement model including 35 items show a good fit to the $\operatorname{data}\left(\chi^{2} / \mathrm{df}=2.054, \mathrm{RMSEA}=0.050, \mathrm{GFI}=0.867, \mathrm{CFI}=0.905\right.$, $\mathrm{TLI}=0.900)$; for the post-performance appraisal questionnaire, two-factor measurement model including 17 items also show a good fit to the $\operatorname{data}\left(\chi^{2} / \mathrm{df}=2.241\right.$, RMSEA $=0.054$, GFI $=0.932$, $\mathrm{CFI}=0.971$, TLI=0.965). It indicates that the overall questionnaire has good validity.

Table I Fitting index values of the model $(n=428)$

\begin{tabular}{ccccccccc}
\hline Fit index & $\chi^{2}$ & $\mathrm{df}$ & $\chi^{2} / \mathrm{df}$ & GFI & CFI & TLI & IFI & RMSEA \\
\hline $\begin{array}{c}\text { Five-factor } \\
\text { model }\end{array}$ & 1129.828 & 550 & 2.054 & 0.867 & 0.905 & 0.900 & 0.905 & 0.050 \\
$\begin{array}{c}\text { Two-factor } \\
\text { model }\end{array}$ & 250.961 & 112 & 2.241 & 0.932 & 0.971 & 0.965 & 0.972 & 0.054 \\
\hline
\end{tabular}

Then we check the correlation between TPA, TNA, POPS, perception justice of system, perception justice of rater. As shown in table II, TPA is significant negatively correlated with POPS, TNA is significant positively correlated with POPS; TPA is significant positively correlated with perception justice of system and rater, TNA is significant negatively correlated with perception justice of system and rater, POPS is significant negatively correlated with perception justice of system and rater. Therefore, the preliminary results is consistent with the hypothesis, we can further 
test the causal relationship between variables.

Table II Means, Standard Deviation, Correlations and Reliabilities(n=428)

\begin{tabular}{cccccccc}
\hline & M & SD & 1 & 2 & 3 & 4 & 5 \\
\hline TPA & 3.509 & 0.575 & 1 & & & & \\
TNA & 2.340 & 0.671 & $-.507^{* *}$ & 1 & & & \\
POPS & 2.651 & 0.699 & $-.426^{* *}$ & $.471^{* *}$ & 1 & & \\
PJS & 3.838 & 0.802 & $.348^{* *}$ & $-.319^{* *}$ & $-.290^{* *}$ & 1 & \\
PJR & 4.108 & 0.813 & $.456^{* *}$ & $-.405^{* *}$ & $-.411^{* *}$ & $.464^{* *}$ & 1 \\
\hline
\end{tabular}

Note: ${ }^{* *}$ indicates $\mathrm{p}<0.01$; ${ }^{*}$ indicates $\mathrm{p}<0.05$;PJS= perception justice of system; $\mathrm{PJR}=$ perception justice of raters; TPA = trait positive affect; TNA= trait negative affect; POPS= perception of organizational politics.

In order to explore the mediating effect of POPS between trait affect and procedural justice perception in performance appraisal, according to the intermediary test method, we will conduct hierarchical regression analysis.

(1) The effect of trait affect on procedural justice perception in performance appraisal

The results of regression analysis showed that TPA has a significant positive effect on PJS(Table III, M1, $\beta=0.251, p<0.001$ ), TPA also has significant positive effect on PJR(Table IV, M4, $\beta=0.338$, $\mathrm{p}<0.001$ ), H1a and H2a were supported. In addition, TNA has a significant negative effect on PJS(Table III, M1, $\beta=-0.170, \mathrm{p}<0.001$ ) , TPA has significant negative effect on PJR(Table IV, M4, $\beta=-0.218, \mathrm{p}<0.001), \mathrm{H} 1 \mathrm{~b}$ and H2b were supported.

(2) The effect of POPS on procedural justice perception in performance appraisal

The results of regression analysis indicated that POPS has a significant negative effect on PJS(Table III, M3, $\beta=-0.112, \mathrm{p}<0.05$ ), POPS also has a significant negative effect on PJR(Table IV, M3, $\beta=-0.205, p<0.001$ ), therefore, H3 were supported.

(3) The mediating effect of perception of organizational politics

Table III shows: in the first step(M1), after controlling the demographic variables, the independent variable TPA has a significant positive effect on PJS, TNA has a significant negative effect on PJS; in the second step(M2), after controlling the demographic variables, the independent variable TPA has a significant negative effect on mediator variables POPS, TNA has a significant positive effect on mediator variables POPS; in the last step, after controlling the demographic variables, introducing TPA, TNA and POPS, POPS has a significant negative effect on PJS, meanwhile the regression coefficients of TPA and TNA were significantly decreased(TPA regression coefficient decreased to 0.223, TNA regression coefficient decreased to -0.134). Therefore, POPS play a partial mediation effect between TPA and PJS, POPS play a partial mediation effect between TNA and PJS, thus H4a was supported.

Similarly, Table IV shows that POPS plays an intermediary role between TPA and PJR, POPS plays an intermediary role between TNA and PJR, H4b is supported. 
Table III Regression analysis of the mediating effect of POPS between trait affect and PJS ( $\mathrm{n}=428$ )

\begin{tabular}{|c|c|c|c|c|c|c|}
\hline \multirow{2}{*}{ Variables } & \multicolumn{2}{|c|}{ PJS } & \multicolumn{2}{|c|}{ POPS } & \multicolumn{2}{|c|}{ PJS } \\
\hline & \multicolumn{2}{|c|}{ M1 } & \multicolumn{2}{|c|}{ M2 } & \multicolumn{2}{|c|}{ M3 } \\
\hline \multicolumn{7}{|l|}{ Control variables } \\
\hline Gender & .000 & .003 & -.044 & -.048 & .000 & -.003 \\
\hline Marital status & .120 & .070 & -.091 & -.026 & .120 & .067 \\
\hline Age & -.010 & -.004 & .100 & .095 & -.010 & .007 \\
\hline Education & $.129^{*}$ & .092 & $-.217^{* * *}$ & $-.155^{* *}$ & $.129^{*}$ & .074 \\
\hline $\begin{array}{l}\text { Organizational tenure } \\
\text { Independent } \\
\text { variable }\end{array}$ & -.053 & -.031 & -.066 & -.099 & -.053 & -.042 \\
\hline TPA & & $.251^{* * *}$ & & $-.257^{* * *}$ & & $.223^{* * *}$ \\
\hline TNA & & $-.170^{* * *}$ & & $.317^{* * *}$ & & $-.134^{*}$ \\
\hline \multicolumn{7}{|l|}{$\begin{array}{l}\text { Mediator } \\
\text { variables }\end{array}$} \\
\hline POPS & & & & & & $-.112^{*}$ \\
\hline $\mathrm{R} 2$ & .028 & .161 & .049 & .291 & .028 & .169 \\
\hline$\triangle \mathrm{R} 2$ & & .132 & & .242 & & .141 \\
\hline $\mathrm{F}$ & $2.472^{*}$ & $11.475^{* * *}$ & $4.336^{* * *}$ & $24.591^{* * *}$ & $2.472^{*}$ & $10.684^{* * *}$ \\
\hline$\Delta \mathrm{F}$ & & $33.044^{* * *}$ & & $71.603^{* * *}$ & & $23.706^{* * *}$ \\
\hline
\end{tabular}

Note: PJS= perception justice of system; TPA= trait positive affect; TNA= trait negative affect; POPS= perception of organizational politics; ${ }^{* * *}$ indicates $\mathrm{p}<0.001 ;{ }^{* *}$ indicates $\mathrm{p}<0.01$; ${ }^{*}$ indicates $\mathrm{p}<0.05$.

Table IV Regression analysis of the mediating effect of POPS between trait affect and PJR $(n=428)$

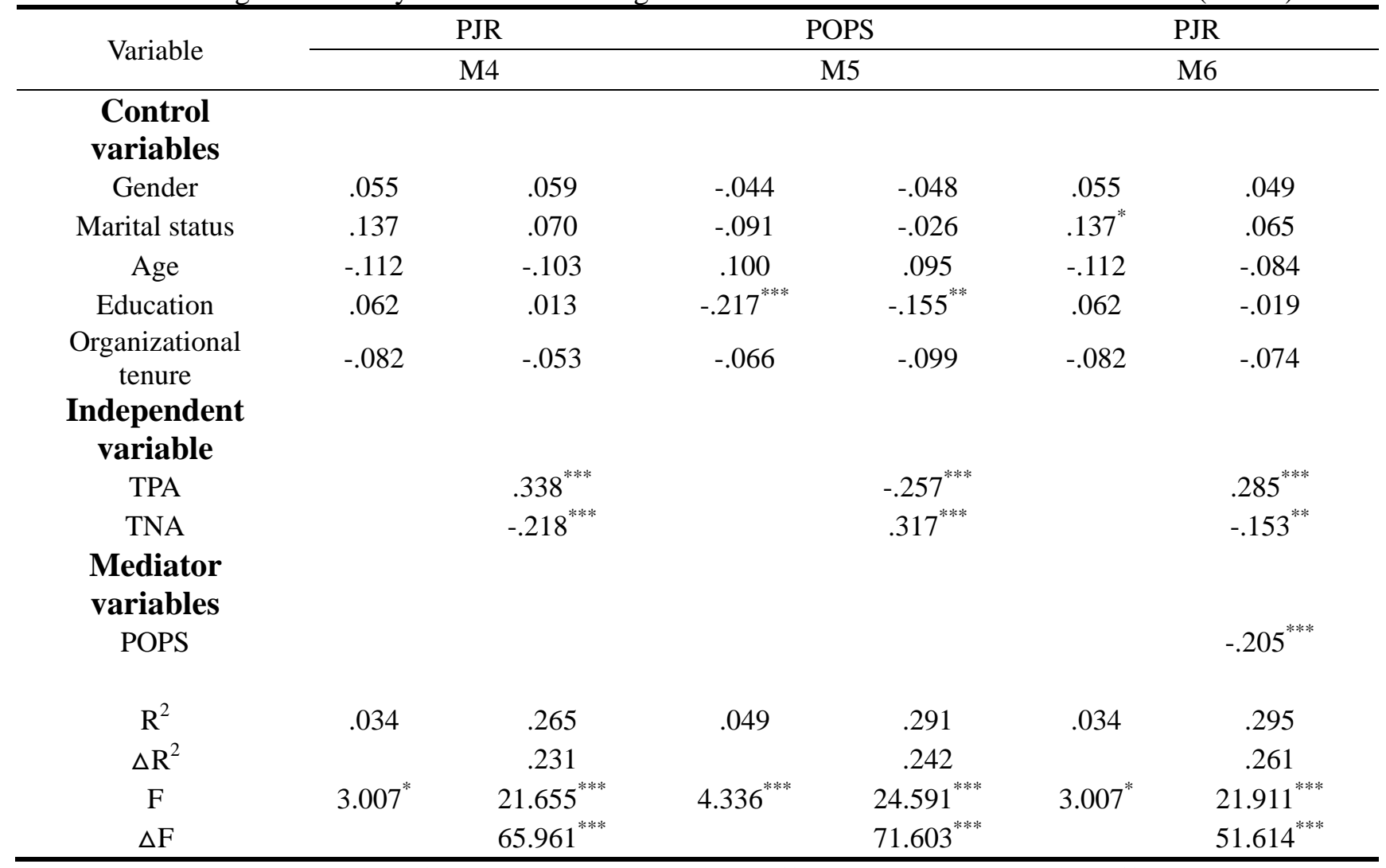

Note: $\mathrm{PJR}=$ perception justice of raters; $\mathrm{TPA}=$ trait positive affect; $\mathrm{TNA}=$ trait negative affect; $\mathrm{POPS}=$ perception of organizational politics; ${ }^{* * *}$ indicates $\mathrm{p}<0.001$; $^{* *}$ indicates $\mathrm{p}<0.01$; ${ }^{*}$ indicates $\mathrm{p}<0.05$. 


\section{Discussion}

Through theoretical analysis and empirical research, this study draws the following conclusions:

Trait positive affect has a significant positive effect on the perception justice of the system and raters, trait negative affect has a significant negative effect on the perception justice of the system and raters. Individuals with different trait affect form different types of cognitive biases, which will affect their work experience and work evaluation. When individuals experience performance evaluation event, the ratees who have positive affectivity are more sensitive to positive emotional events in the appraisal process. Moreover, one would expect high TPA ratees, because of their positive traits and good interpersonal interactions, to experience more positive interactional treatment in the performance appraisal process, resulting in a high perception of procedural justice. Conversely, High TNA ratees are more sensitive to negative emotions in the performance appraisal process, and their negative pessimistic nature would make them suffer more unfair interpersonal behavior, leading to a lower sense of procedural justice in performance appraisal.

Secondly, POPS has a significant negative effect on the perception justice of the system and raters, which indicates that the stronger the political behavior of the organization they perceive, the more likely they consider the performance appraisal system and the raters who carry out the evaluation procedure unfair. Organizational politics usually involves the distribution of valuable resources. In human resource management activities, performance evaluation and resource allocation are closely related. Individual's political perception will directly affect their judgment of performance evaluation system. In this study, in order to identify the source of procedural justice perceptions in performance appraisal, we adopted Chen's multifocal research results which classifying the procedural justice perceptions in performance appraisal into perception justice of system and perception justice of raters. Our research shows that ratees' POPS has a significant negative effect on the two dimensions of procedural justice perceptions of performance appraisal, indicating that others in the organization will take various political behaviors to achieve their own profit, the higher the degree of individual's awareness of this behavior, the more likely they will produce a sense of procedural injustice.

Finally, this research show that POPS plays a partial role of mediating between trait affect and perception justice of the system and raters. POPS are thought to be experiential, individual trait differences are likely to produce different interpretations of political perception and further influence the subsequent response patterns. In the context of performance evaluation, as a kind of personality traits, trait affect will influence the degree of perception of political behavior, and this degree of perception will further affect the ratee's response to the performance appraisal process. High TPA ratees usually are enthusiastic, energetic and positive. They perceived less self-interested behavior of organizations and raters, therefore they feel that the evaluation process is fair. High TNA ratees are more sensitive to negative stimulus, have stronger sense of insecurity, and perceive intense environmental stress, thus are more likely to observe evaluation system is manipulated by others from organizational focus and perceive injustice of raters from rater focus, resulting in procedural injustice perceptions in performance appraisal.

\section{Implications and limitations}

Through theoretical and empirical research, implications can be drawn as followed: Before conduct performance evaluation, enterprises should establish a relatively complete system of rater training, increase objective appraisal indicators, and make raters aware of high TNA ratees will perceived lower procedural justice. Moreover, organizations and raters should give ratees more opportunity of participation and voice, as well as provide detailed, formal communication and feedback for high TNA ratees during performance feedback process. On the other hand, although organizational politics is unavoidable, it also can be controlled within reasonable range. Organizations can establish a high cohesion work environment, create a harmonious corporate culture, reduce the presence of "influential" groups, strengthen the supervision of performance appraisal process, and reduce high TNA ratees’ stress and vigilance. 
Furthermore, this study has obtained some valuable conclusions, but there are still some deficiencies, future research can be conducted from the following aspects: the survey of this study mainly concentrated in Anhui province and Shanghai city, sample data may have some regional features. Future research can choose to select research sample in a larger range. In addition, political behavior is an objective existence, different organizations will have different intensity political climate. In other words, there will be differences of perceptions of politics for the same individuals who is under distinguishing political climate, future research can consider the moderating effect of organizational political climate when you study the antecedents of procedural justice perceptions in performance appraisal.

\section{References}

[1] Colquitt J A, Scott B A, et al. Justice at the millennium, a decade later: A meta-analytic test of social exchange and affect-based perspectives [J]. Journal of Applied Psychology, 2013, 98(2): 199-236..

[2] Watson D, Clark L A, Tellegen A. Development and validation of brief measures of positive and negative affect: The PANAS scales [J]. Journal of Personality and Social Psychology, 1988, 54(6): $1063-1070$.

[3] Barsky A, Kaplan S A. If you feel bad, it's unfair: A quantitative synthesis of affect and organizational justice perceptions [J]. Journal of Applied Psychology, 2007, 92: 286-295.

[4] Chen L F. Research on justice perceptions in performance appraisal: structure, antecedents and effects [M]. Beijing, Science Press, 2014.

[5] Ng T W H, Sorensen K L. Dispositional affectivity and work-related outcomes: A meta-analysis [J]. Journal of Applied Social Psychology, 2009, 39(6): 1255-1287.

[6] Kacmar K M, Carlson D S. Further validation of the perceptions of politics scale (POPS): A multiple sample investigation [J]. Journal of Management, 1997, 23(5): 627-658.

[7] Dulebohn J H, Ferris G R. The role of influence tactics in perception of performance evaluations' fairness [J]. Academy of Management Journal, 1999, 42(3): 288-303.

[8] Atinc G, Darrat M, Fuller B. Perceptions of organizational politics: A meta-analysis of theoretical antecedents [J]. Journal of Managerial Issues, 2010, 22(4): 494-513.

[9] Chang C, Rosen C C, Levy P E. The relationship between perceptions of organizational politics and employee attitudes, strain, and behavior: A meta-analytic examination [J]. Academy of Management Journal, 2009, 52(4):779-801. 